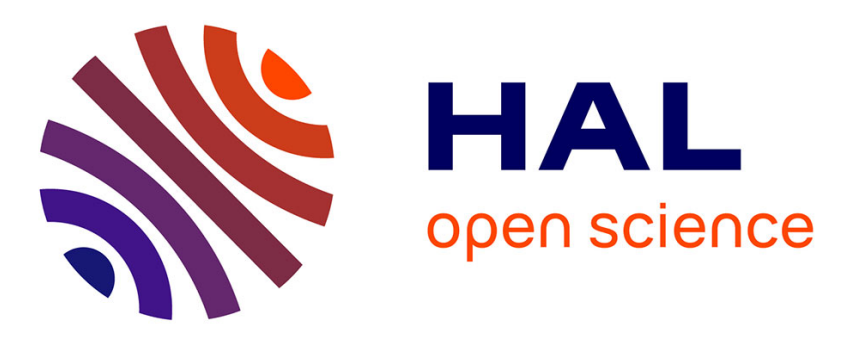

\title{
Glacier flow monitoring by digital camera and space-borne SAR images
}

Flavien Vernier, Renaud Fallourd, Jean-Michel Friedt, Yajing Yan, Emmanuel Trouvé, Jean-Marie Nicolas, Luc Moreau

\section{- To cite this version:}

Flavien Vernier, Renaud Fallourd, Jean-Michel Friedt, Yajing Yan, Emmanuel Trouvé, et al.. Glacier flow monitoring by digital camera and space-borne SAR images. Image Processing Theory, Tools and Applications (IPTA), 2012, Oct 2012, Turkey. pp.25 - 30, 10.1109/IPTA.2012.6469541 . hal00936106

\section{HAL Id: hal-00936106 https://hal.science/hal-00936106}

Submitted on 24 Jan 2014

HAL is a multi-disciplinary open access archive for the deposit and dissemination of scientific research documents, whether they are published or not. The documents may come from teaching and research institutions in France or abroad, or from public or private research centers.
L'archive ouverte pluridisciplinaire HAL, est destinée au dépôt et à la diffusion de documents scientifiques de niveau recherche, publiés ou non, émanant des établissements d'enseignement et de recherche français ou étrangers, des laboratoires publics ou privés. 


\title{
Glacier flow monitoring by digital camera and space-borne SAR images
}

\author{
Flavien Vernier ${ }^{1}$, Renaud Fallourd ${ }^{12}$, Jean Michel Friedt ${ }^{3}$, Yajing Yan $^{4}$, \\ Emmanuel Trouvé ${ }^{1}$, Jean-Marie Nicolas ${ }^{1}$ and Luc Moreau ${ }^{5}$ \\ ${ }^{1}$ Université de Savoie-Polytech Annecy-Chambéry-LISTIC, BP 80439, 74944 Annecy-le-Vieux cedex, France \\ email: \{flavien.vernier, renaud.fallourd and emmanuel.trouve\}@univ-savoie.fr \\ ${ }^{2}$ Institut TELECOM, TELECOM ParisTech, CNRS LTCI, 75013 Paris, France \\ email: jean-marie.nicolas@telecom-paristech.fr \\ 3 Département LPMO, Institut FEMTO-ST, 25044 Besançon cedex, France \\ email: jean-michel.friedt@femto-st.fr \\ ${ }^{4}$ IETR, Université de Rennes 1, Campus de Beaulieu, CS 7425035042 Rennes cedex, France \\ email: yajing.yan@univ-rennes1.fr \\ ${ }^{5}$ EDYTEM, CNRS, Université de Savoie, 73376 Le Bourget du Lac cedex, France \\ email: moreauluc@club-internet.fr
}

\begin{abstract}
Most of the image processing techniques have been first proposed and developed on small size images and progressively applied to larger and larger data sets resulting from new sensors and application requirements. In geosciences, digital cameras and remote sensing images can be used to monitor glaciers and to measure their surface velocity by different techniques. However, the image size and the number of acquisitions to be processed to analyze time series become a critical issue to derive displacement fields by the conventional correlation technique. In this paper, an efficient correlation software is used to compute from optical images the motion of a serac fall and from Synthetic Aperture Radar (SAR) images the motion of Alpine glaciers. The optical images are acquired by a digital camera installed near the Argentière glacier (Chamonix, France) and the SAR images are acquired by the high resolution TerraSAR-X satellite over the Mont-Blanc area. The results illustrate the potential of this software to monitor the glacier flow with camera images acquired every $2 \mathrm{~h}$ and with the size of the TerraSAR-X scenes covering $30 \times 50 \mathbf{k m}^{2}$.
\end{abstract}

\section{INTRODUCTION}

In the last decades, the warmer climate, together with less precipitation in the glacial accumulation areas, has resulted in a spectacular retreat of most of the monitored temperate glaciers [1]. If confirmed in the coming years, this evolution will have important consequences in terms of water resources, economical development and risk management in the surrounding areas. To monitor glacier displacements and surface evolutions, two main complementary sources of information are available:

- in-situ data collected for instance using accumulation/ablation stakes, Global Positioning System (GPS) stations, or digital cameras installed near the glaciers to acquire regular images of specific areas such as serac falls, unstable moraines ...

- remote sensing data acquired by air-borne or space-borne sensors such as multispectral optical images or Synthetic Aperture Radar (SAR) images.
Optical data sets are often used to observe changes and allow the computation of high resolution (HR) information such as the surface elevation or glacier displacement fields during the summer [2], [3], [4], but they cannot be regularly acquired along the year and efficiently used because of clouds or snow cover uniformity. Space-borne SAR data, especially the recently lunched HR satellites such as TerraSAR-X, COSMOSkyMed or Radarsat-2, are a new source of information which may allow global evolution monitoring and provide regular measurements thanks to the all-weather capabilities of SAR imagery. They are used to derive surface changes and velocity fields [5], or to detect and track rocks and crevasses [6].

Image co-registration performed by the well-known correlation technique is a classical technique to detect changes or displacements. Several tools have been developed to solve the classical correlation problem with optical or SAR images: Co-registration of Optically Sensed Images and Correlation (COSI-Corr) [7], [8], Repeat Orbit Interferometry Package (ROI-PAC) [9]. A disadvantage of these tools is that the computation time can dramatically increase with the image size and the number of correlation points in the image. There are many different techniques developed for image coregistration [10], [11]. Those based on sub-image correlation operate either in the temporal domain (the spatial domain for the 2 dimensional (2D) signal images) by directly computing the values of the cross-correlation function and searching for its peak, or in the spectral domain after the computation of the discrete Fourier transform of the two sub-images [12]. A constraint of the spectral domain is the window size which must be a power of 2 in both directions to benefit from the FFT optimizations.

In this paper, an improved implementation strategy of the correlation function in the spatial domain is used [13]. The objective is to preserve the flexibility and the genericness of the spatial domain approach, and to benefit from the computation efficiency of parallel or distributed processing architectures. The originality of this approach is to be able to efficiently 
compute the disparity measure at the initial resolution and to derive a dense displacement field. The potential and the performances of this approach are illustrated on two kinds of data: remote sensing data with repeated pass acquisitions of HR TerraSAR-X images over fast moving glaciers in the Alps, and proximal sensing image time series from a digital camera installed in front of a serac fall of the Argentière glacier in the Mont-Blanc area.

This paper is organized as follows: Section II details the Normalized Cross-Correlation (NCC) algorithm. In the next sections, Sections III and IV, the correlation software is applied to a realistic problem. Section III is dedicated to the computation of the displacement of a serac fall in the lower part of the Argentière glacier. The results show a set of serac displacements and highlight the impacts of the optimized software. Section IV illustrates the computation of glacier flow by correlation of SAR images. This section confirms the results obtained with optical images and shows the impact of the master window size on the computation time. Finally, Section V concludes this paper and projects future work.

\section{MOTION ESTIMATION ALGORITHM: CORRELATION}

The objective of the correlation consists in finding the best match between sub-images, a slave image $I^{\prime}$ compared with a master image $I$. The master window $M$ and the search window $S$ are, respectively, defined by their numbers of rows $M_{\mathrm{r}}$ and $S_{\mathrm{r}}$ and their numbers of columns $M_{\mathrm{c}}$ and $S_{\mathrm{c}}$. We consider that the size, $M_{\mathrm{r}}, M_{\mathrm{c}}, S_{\mathrm{r}}$ and $S_{\mathrm{c}}$ are odd. In this manner, the correlation objective is finding for each point $(k, l)$ of the master image, the best position of the window $M_{k, l}$ centered on $(k, l)$ in $S_{k, l}$, according to a similarity function $D(p, q)$, where $p$ and $q$ are the displacements of $M_{k, l}$ in $S_{k, l}$. The search window definition implies that $S_{\mathrm{r}} \geq M_{\mathrm{r}}$ and $S_{\mathrm{c}} \geq$ $M_{\mathrm{c}}$, in this way, $S_{\mathrm{c}}-M_{\mathrm{c}}$ is maximum of displacement in column (left + righ) and $S_{\mathrm{r}}-M_{\mathrm{r}}$ is maximum of displacement in row (up + down). The best position $(\hat{p}, \hat{q})$ is defined by the maximum of the similarity function for a given couple $\left(M_{k, l}, S_{k, l}\right)$ :

$$
D_{k, l}(\hat{p}, \hat{q})=\max _{p, q}\left(D_{k, l}(p, q)\right) .
$$

The similarity function $D(p, q)$ is not fixed and depends on the user needs. In this paper, the classical NCC defined by Equations 2, 3 and 4 is used.

$$
D_{k, l}(p, q)=\frac{\sum_{i, j} P_{k, l}(p, q, i, j)}{N_{k, l}(p, q)},
$$

where

$$
P_{k, l}(p, q, i, j)=M(i, j) \cdot S(i-p, j-q),
$$

and

$$
N_{k, l}(p, q)=\sqrt{\sum_{i, j} M(i, j)^{2} \cdot \sum_{i, j} S(i-p, j-q)^{2}} .
$$

The correlation result is the computation of $(\hat{p}, \hat{q})$ for all $(k, l)$ such that $\frac{S_{\mathrm{r}}}{2} \leq k \leq I_{\mathrm{r}}-\frac{S_{\mathrm{r}}}{2}+1$ and $\frac{S_{\mathrm{c}}}{2} \leq l \leq$ $I_{\mathrm{c}}-\frac{S_{\mathrm{c}}}{2}+1$. Thus, for each point, the result is defined by $\hat{p}, \hat{q}$ and $D_{k, l}(\hat{p}, \hat{q})$. The values of $\hat{p}, \hat{q}$ are, respectively, the displacement on the lines and the displacement on the columns of the point $(k, l)$, and $D_{k, l}(\hat{p}, \hat{q})$ is the cross-correlation level for these displacements, which varies between 0 and 1 .

According to our constraints, we implement an optimized NCC algorithm. The first objective of the optimization is to avoid re-computing an already computed value. The second one is to introduce a flow computation technique to reduce the number of operations of the algorithm. These two techniques are the well-known summed-area tables algorithms [14]. They have been more recently used in the method proposed by Viola and Jones [15] for object fast detection.

This optimized implementation is available in the Extraction and Fusion of Information for ground Displacement measurements with Radar Imagery (EFIDIR) Tools under GNU General Public License (GPL). These tools can be downloaded from the EFIDIR web site (see Acknowledgments).

\section{EXPERIMENTS AND RESULTS ON DIGITAL VIDEO CAMERA IMAGES}

At the beginning of the twenty-first century, digital photography development has made the glacier flow monitoring with HR digital cameras possible. Up to now, only few experiments have been reported with HR digital cameras, as for example in Greenland polar glaciers [16], [17].

\section{A. Digital camera data set}

Since 2007, in the framework of the ANR (French National Research Agency) Hydro-Sensor-FLOWS project, HRautomated digital cameras have been developed and installed around the Mont-Blanc massif (Argentière, Mer de Glace, Bionnassay and Trient glaciers). In this paper, one of the Argentière cameras is used: the camera installed at 2,300 m Above Sea Level (ASL) which is focused on "Lognan serac fall".

The HR-automated digital cameras installed around the Mont-Blanc massif are based on customized Leica DLux 3 and DLux 4 units. The configuration is to wake up at 8 a.m. local time and grab six images every day, with $2 \mathrm{~h}$ intervals between images. The system grabs 16:9 HR images of 10 Mega pixels $(4,224 \times 2,376$ pixels $)$ with the same field of view over time. The angle of view of the camera is calibrated to $65^{\circ}$, with a width of 4,224 pixels, the angle of view of a single pixel is $0.015^{\circ}$ (aperture angle) [18].

\section{B. Processing}

All the images are stored as HR JPEG images: this format was selected as a compromise between storage efficiency (since the cameras are running autonomously for up to 6 months without supervision) and data quality. These images acquired over "Lognan serac fall" are processed in three steps:

1) The initial RGB JPEG images $I_{\text {jpeg }}$ are converted in grayscale images $I_{\text {gray }}$ to obtain mono-band images that is compatible with fast correlation approach. This conversion is processed according to the following formula:

$$
I_{\text {gray }}=0.30 \times I_{\text {Red }}+0.59 \times I_{\text {Green }}+0.11 \times I_{\text {Blue }} .
$$


The resulting image is typically called luminance in the digital image processing domain [19].

2) An initial co-registration between the images is made on the motion-free part of the images to correct camera motion due to extreme weather conditions above 2, $000 \mathrm{~m}$ ASL (wind, strong temperature variations) [20]. In practice, the motion-free parts, i.e. mountains on the background, are used to perform it. This initial image co-registration on motion-free areas is realized by a translation without applying sub-pixel offsets.

3) The fast correlation technique is applied on the image pair with $31 \times 31$ pixels master window (i.e. $M_{\mathrm{r}} \times$ $M_{\mathrm{c}}$ ) and $51 \times 51$ pixels slave window (i.e. $S_{\mathrm{r}} \times S_{\mathrm{c}}$ ), corresponding to a maximum offset of 10 pixels in each direction. On motion-free areas, the sub-pixel offsets provide an accurate estimation of the remaining offset due to the camera instability. On the glacier, the measured offset is the sum of the displacement offset and the geometrical offset which has not been compensated for at step 2 .

The correlation results obtained are illustrated by the magnitude and the orientation of the pixel offset vector in Figure 1. This result is obtained in 80 minutes with an Intel(R) Core(TM) i7 $3 \mathrm{GHz}$, and the gain is quasi linear if the distributed implementation is used. The values close to zero (in black) on magnitude correspond to the motionfree parts around the Argentière glacier which are well coregistered by the initial translation (step 2). The areas in purple correspond to the motion-free parts where there are remaining offset variations due to the camera rotation [20]. The glacier displacement appears with stronger magnitude in blue, green and yellow colors. The heterogeneity is due to either the glacier flow physics or the scene configuration: the nearest parts of the glacier appear to be flowing faster than the farthest parts. The displacement map of Figure 1(b) highlights the differences between the ice blocks in the foreground (mostly in yellow), in the middle distance (mostly in green) and in the background (mostly in blue). One can notice a large ice block in green color on the right part of the blue background, corresponding to a larger displacement: this ice block is about to fall. There are also a few parts where the magnitude and the orientation maps look like noise and inconsistence. These parts correspond to ice falls which happened between the two image acquisitions.

\section{EXPERIMENTS AND RESULTS ON SAR IMAGES}

Contrary to the optical images, the space-borne images cover large areas. The whole glacier surface, and even all the glaciers of a mountain area, can be observed simultaneously.

\section{A. TerraSAR-X data set}

Our TerraSAR-X data set includes 35 stripmap images on the Mont-Blanc test site with different orbits (descending/ascending), different polarisations $(\mathrm{HH}, \mathrm{HH} / \mathrm{VV}$ and $\mathrm{HH} / \mathrm{HV}$ ) and different continuous series. In this paper, the cross-correlation results are illustrated on the single polarization $(\mathrm{HH})$ descending images which are acquired with an

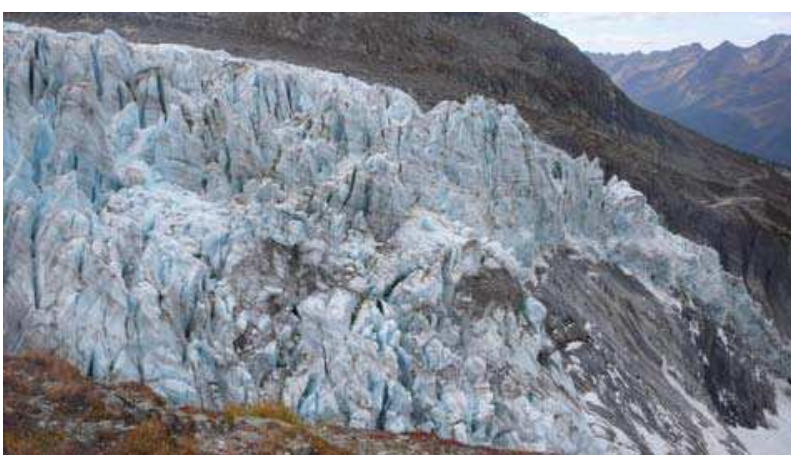

(a) JPEG image 2008-10-09 (4, 224 × 2, 376 pixels).

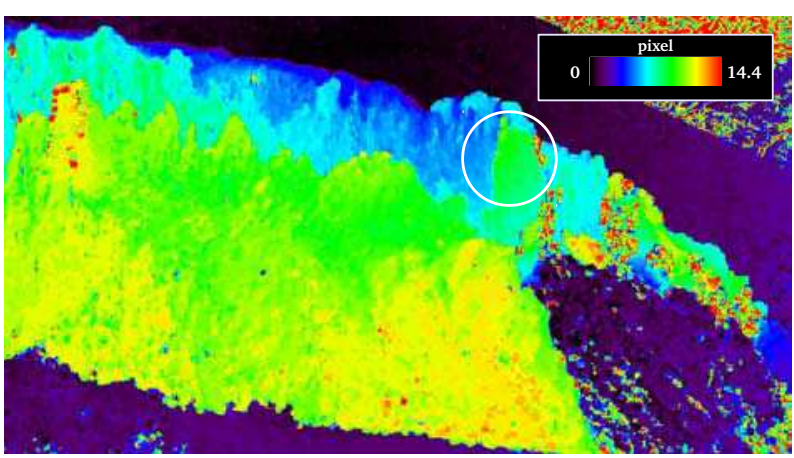

(b) Magnitude of the 2D displacement measured in the two directions of image plane.

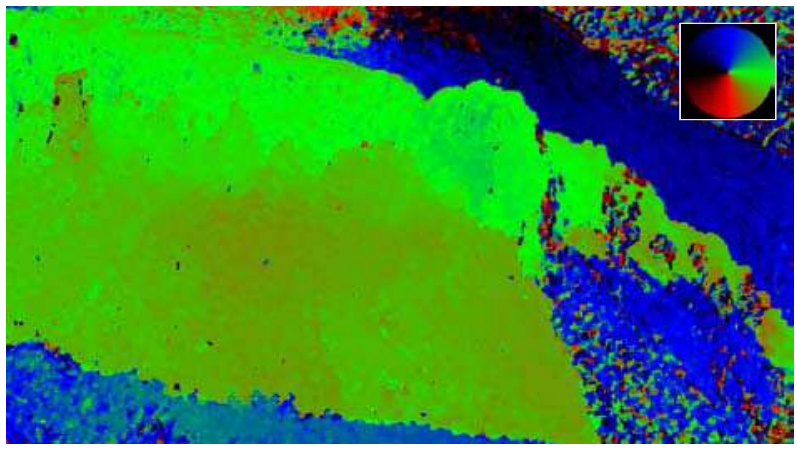

(c) Orientation of the $2 \mathrm{D}$ displacement (color reference on the top right corner).

Fig. 1. Displacement field over the Argentière glacier derived by NCC between digital camera image pair (2008-10-09/2008-10-10).

incidence angle of $37^{\circ}$ and a spacing of $1.36 \mathrm{~m}$ per pixel in range and $2.04 \mathrm{~m}$ per pixel in azimuth direction. The range and azimuth image axes correspond to the radar line of sight (LOS) and the sensor displacement direction, respectively. The stripmap mode has been chosen because it supplies a large scene coverage (about $30 \times 50 \mathrm{~km}^{2}$ ) and $\mathrm{HR}$ at the same time. Figure 2 shows a whole strip-map image which covers almost the whole Mont-Blanc area, i.e. French, Italian and Swiss parts.

\section{B. Processing}

In the mountainous areas where most of the Alpine glaciers are located, the "range sampling" of SAR images introduces strong geometrical distortions. To avoid geocoding artifacts, the SAR images of the Mont-Blanc test site have been or- 


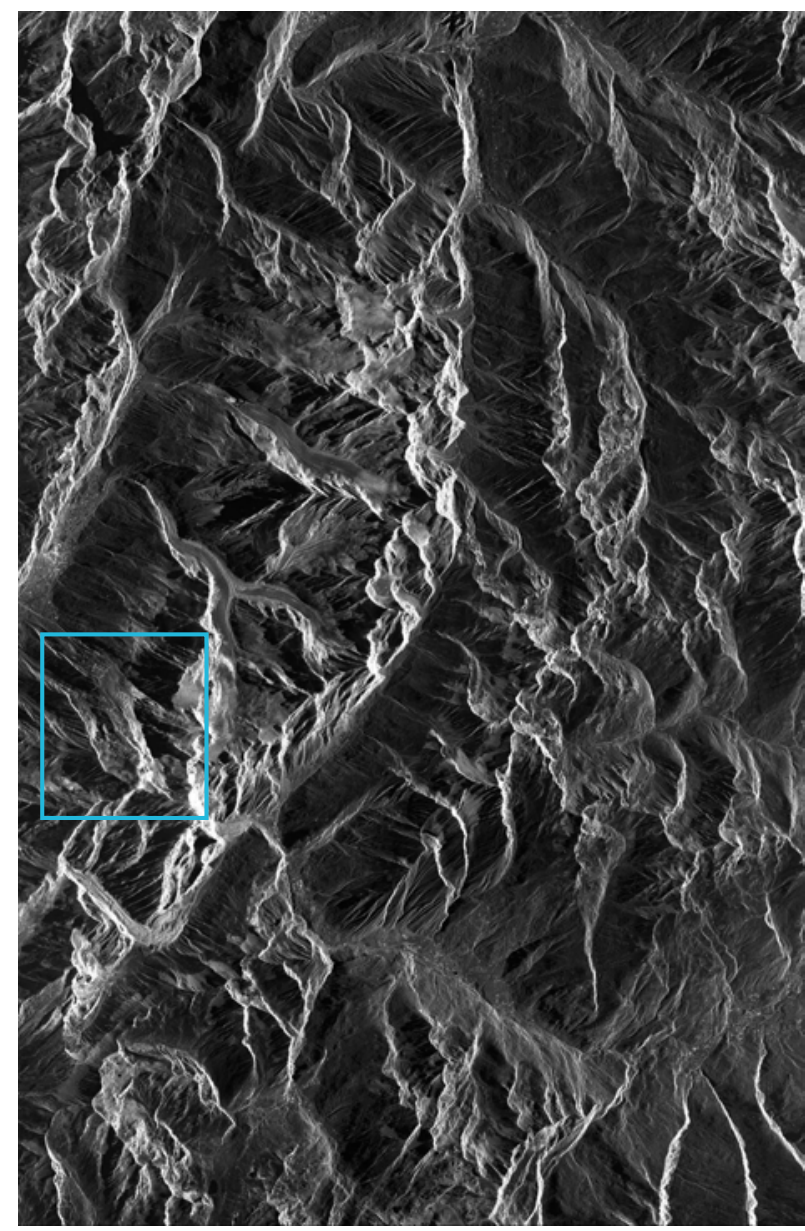

Fig. 2. TerraSAR-X amplitude strip-map image $(15,790 \times 24,183$ pixels $)$, Mont-Blanc area, 2008-09-29 (averaged by $10 \times 10$ for display). The blue rectangle corresponds to the sub-image chosen to illustrate glacier displacements in Figure 4.

dered in their initial geometry. The offsets measured in range direction between two images are sensitive to the position along the swath (near range $\mathrm{e}^{1} /$ far range $^{2}$ ), to the topography, as well as to the surface displacement occurred between the two acquisition dates. The offsets measured in azimuth direction mainly depend on the surface displacement (a linear correction is sufficient to remove along-track registration variations over long scenes). The range variations due to the topography depend on the perpendicular baseline between the two orbits as in a stereo configuration. These variations can be predicted using a Digital Elevation Model (DEM) of the area and the orbital data (antenna state vectors) which are provided together with the images.

In the studied area, the altitude varies between 1,000 $\mathrm{m} \mathrm{ASL}$ (in the Chamonix valley) up to $4,800 \mathrm{~m}$ ASL (on the MontBlanc). For the image pair (2008-09-29/2008-10-10) whose perpendicular baseline is around $138 \mathrm{~m}$, the range registration offsets due to this baseline vary between 28.9 and 82.4 pixels in near and far range, respectively. The glaciers of this test site might move up to $1.5 \mathrm{~m}$ per day in the fastest areas,

\footnotetext{
${ }^{1}$ The portion of a radar image which is the closest to the satellite.

${ }^{2}$ The portion of a radar image which is the farthest from the satellite.
}

according to in situ measurements. The glacier displacements vary between 0 and $16 \mathrm{~m}$ in 11 days, hence $0-8$ pixels with the resolution of the TerraSAR-X images used in this paper.

According to this a priori displacement information, the TerraSAR-X data acquired over the Mont-Blanc test site are processed in three steps:

1) An initial co-registration by a simple translation (without resampling) is applied by matching an area of the image located at an intermediate elevation of about 2,000 m ASL.

2) The proposed fast correlation technique is applied to the whole image with $61 \times 61$ pixels master window (i.e. $M_{\mathrm{r}} \times M_{\mathrm{c}}$ ) and $77 \times 77$ pixels slave window (i.e. $S_{\mathrm{r}} \times S_{\mathrm{c}}$ ), corresponding to an offset of $\pm 16 \mathrm{~m}$ in each direction. On motion-free areas, the sub-pixel offsets provide an accurate estimation of the remaining offset due to the SAR geometry. On the moving glaciers, the measured offset is the sum of the displacement offset and the geometrical offset which has not been compensated for at step 1 .

3) Depending on the variations of the geometrical offset along the glaciers, a post-processing step can be necessary to deduce the offsets only due to the glacier movement. The remaining geometrical offset can be subtracted using either the predictions from the DEM and the orbits, or the results of the sub-pixel correlation around the glaciers.

The correlation results obtained on the whole TerraSAR-X image presented in Figure 2 are illustrated by the magnitude of the offset vector in Figure 3. This result is obtained in 4 hours with an Intel(R) Core(TM) i $3 \mathrm{GHz}$, and the gain is quasi linear if the distributed implementation is used. The values close to zero (in black) correspond to the motion-free areas which are well co-registered by the initial translation (step 1). The remaining offset variation due to the SAR geometry can be observed in the dark and light blue areas. The shapes of moving glaciers (Mer de Glace, Argentière, Les Bossons ...) appear with stronger magnitude in green. Fiure 4 is a zoom on the Taconnaz, the Bossons and the Bionnassay glaciers. The displacement magnitude and orientation show that the motion is not uniform but they are consistent with the glacier behaviors: the velocity is higher in the center of the glacier, and two acceleration areas appear on the Bossons glacier. On the higher part of these glaciers, the magnitude and orientation are very noisy: the correlation technique does not provide reliable results. A larger window size could improve the results on poorly correlated areas, but the window size cannot be very large since the displacement field is not homogeneous over the glaciers and the border discontinuity should be preserved.

\section{CONCLUSIONS AND FUTURE WORK}

This paper illustrates a glacier flow monitoring with an optimized implementation of the NCC algorithm. The computation on each point of the image can be achieved in a reasonable time: $0.02 \mathrm{~min} / \mathrm{mega}$ pixel instead of $0.4 \mathrm{~min} / \mathrm{mega}$ pixel with a conventional approach. This fast correlation technique is very useful to extend experimental researches on high resolution images covering large scenes. 


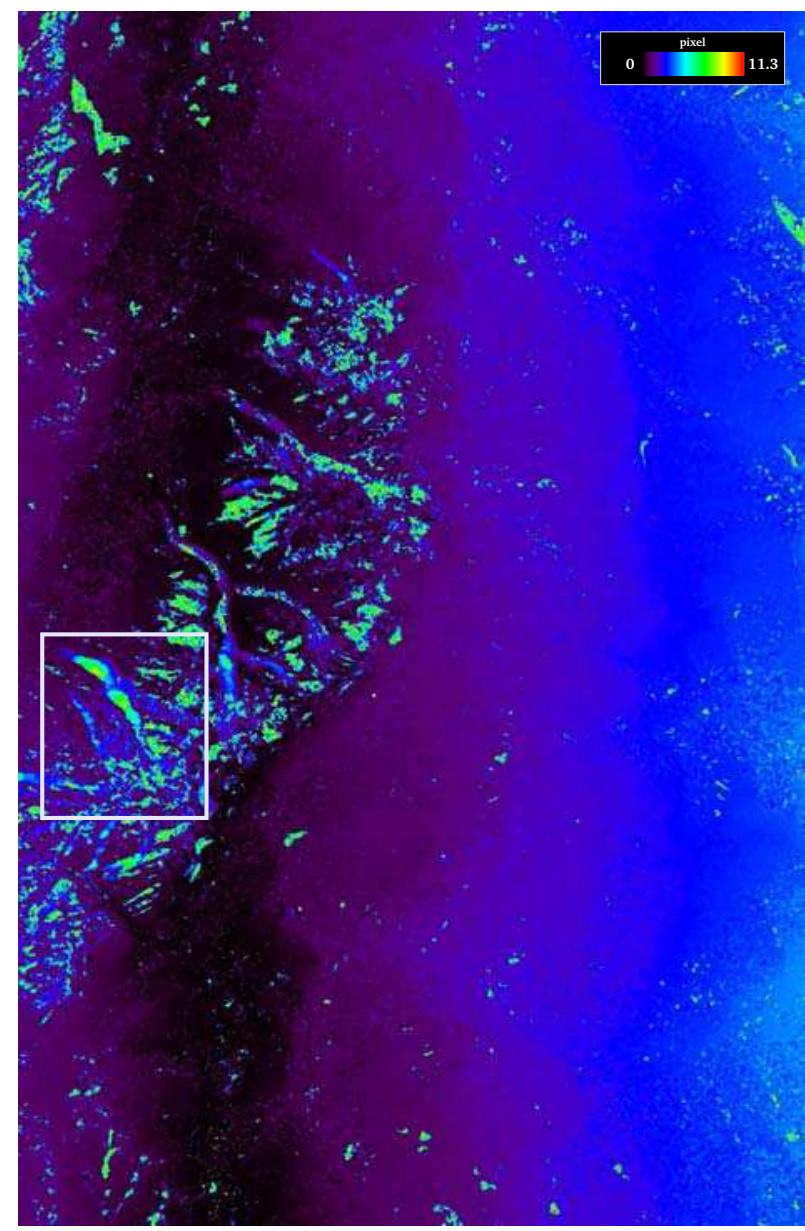

Fig. 3. Magnitude of the offset vector derived by NCC between two TerraSAR-X strip-map images (2008-09-29 and 2008-10-10) over the MontBlanc area (averaged by $10 \times 10$ for display).

The evolution of serac falls is studied with optical images and the whole glacier surface evolution can be observed with SAR images. On the Mont-Blanc area, the correlation reveals particular areas like glaciers, lakes or other changing features that can be studied. These experimental results highlight the potential of proximally and remotely sensed images to monitor the glacier flow and to contribute to risk assessment: the Taconnaz glacier is for instance an important source of risk for the access road to the Mont-Blanc tunnel.

Future work mainly includes two axes. Regarding the optical images, a stereo camera will be installed near Argentière glacier to measure simultaneously the topography and the displacement of the serac fall. Regarding the SAR images, as the NCC is only one of the available similarity functions, the study and the optimization of new criteria, different from the NCC, will also be investigated.

\section{ACKNOWLEDGMENTS}

The authors wish to thank the French Research Agency (ANR) for supporting this work through the Hydro-SensorFLOWS project and the EFIDIR project (ANR-2007-MCDC004, http://www.efidir.fr). They also wish to acknowledge the German Aerospace Agency (DLR) for the TerraSAR-X images

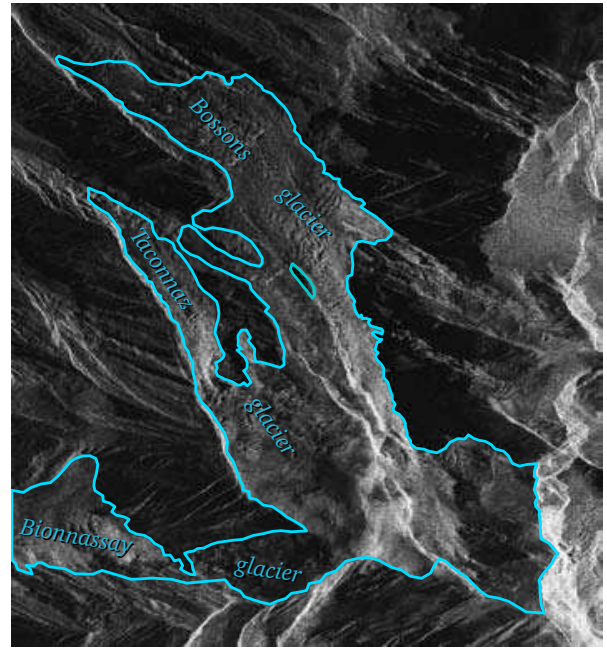

(a) Amplitude sub-image $(3,400 \times 3,700$ pixels $)$.

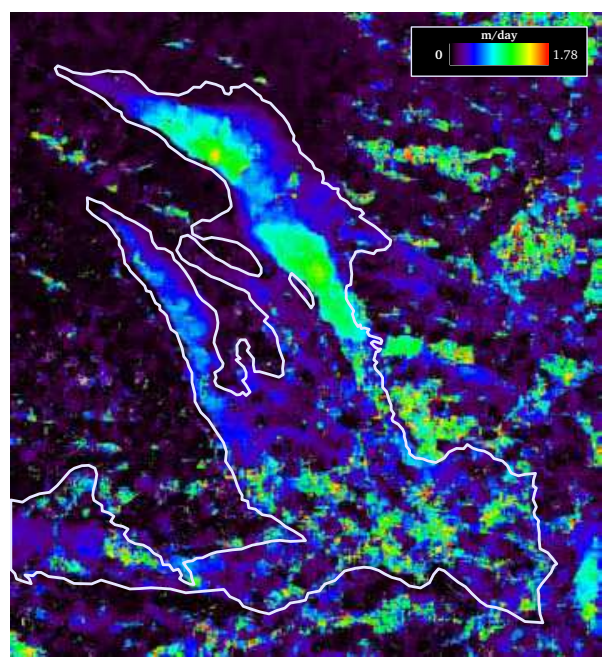

(b) Magnitude of the 2D displacement measured in the range and azimuth directions.

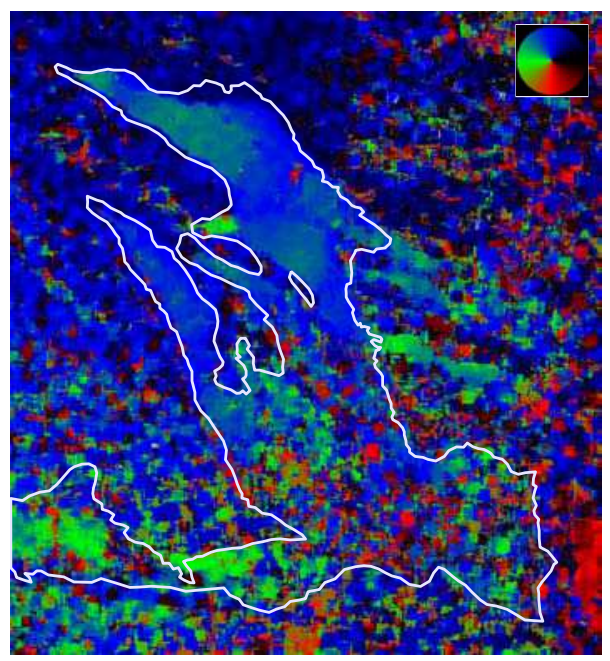

(c) Orientation of the 2D displacement (color reference on the top right corner)

Fig. 4. Displacement field over the Bossons, Taconnaz and Bionnassay glaciers derived by NCC between TerraSAR-X image pair (2008-09-29/200810-10). 
(project MTH0232) and Électricité Emosson SA for their support.

\section{REFERENCES}

[1] C. Vincent, A. Soruco, D. Six, and E. Le Meur. Glacier thickening and decay analysis from 50 years of glaciological observations performed on glacier d'Argentière, Mont Blanc area, France. Annals of Glaciology, 50:73-79, 2009.

[2] E. Berthier, H. Vadon, D. Baratoux, Y. Arnaud, C. Vincent, K.L. Feigl, F. Rémy, and B. Legrésy. Mountain glaciers surface motion derived from satellite optical imagery. Remote Sensing Environ., 95(1):14-28, 2005.

[3] D. Scherler, S. Leprince, and M. R. Strecker. Glacier-surface velocities in alpine terrain from optical satellite imagery-accuracy improvement and quality assessment. Remote Sensing of Environment, 112(10):38063819, 2008.

[4] Ute C. Herzfeld, Garry K. C. Clarke, Helmut Mayer, and Ralf Greve. Derivation of deformation characteristics in fast-moving glaciers. Computers \& Geosciences, 30(3):291 - 302, April 2004.

[5] E. Trouvé, G. Vasile, M. Gay, L. Bombrun, P. Grussenmeyer, T. Landes, J.M. Nicolas, P. Bolon, I. Petillot, A. Julea, L. Valet, J. Chanussot, and M. Koehl. Combining airborne photographs and spaceborne SAR data to monitor temperate glaciers. Potentials and limits. IEEE Transactions on Geoscience and Remote Sensing, 45(4):905-923, 2007.

[6] R. Fallourd, O. Harant, E. Trouvé, J.-M. Nicolas, F. Tupin, M. Gay, G. Vasile, L. Bombrun, A. Walpersdorf, J. Serafini, N. Cotte, F. Vernier, L. Moreau, and $\mathrm{Ph}$. Bolon. Monitoring temperate glacier by multitemporal TerraSAR-X images and continuous GPS measurements. IEEE Journal of Selected Topics in Applied Earth Observations and Remote Sensing, page DOI : 10.1109/JSTARS.2010.2096200, (to appear) 2011

[7] S. Leprince, S. Barbot, F. Ayoub, and J. P. Avouac. Automatic and precise ortho-rectification, coregistration, and subpixel correlation of satellite images, application to ground deformation measurements. IEEE Transactions on Geoscience and Remote Sensing, 45(6):1529-1558, 2007.

[8] S. Leprince, F. Ayoub, Y. Klinger, and J.P. Avouac. Co-registration of optically sensed images and correlation (COSI-Corr): an operational methodology for ground deformation measurements. In IEEE International Geoscience and Remote Sensing Symposium (IGARSS 2007), pages 1943-1946, Barcelona, Spain, July 2007.

[9] P.A. Rosen, S. Hensley, G. Peltzer, and M. Simons. Updated repeat orbit interferometry package released. The Earth Observation System, Transactions, American Geophysical Union, Electronic Supplement, http://www.agu.org, 85(5), 2004.

[10] B. Zitová and J. Flusser. Image registration methods: a survey. Image and Vision Computing, 21(11):977-1000, 2003.

[11] J. Gao and M. B. Lythe. The maximum cross-correlation approach to detecting translational motions from sequential remote-sensing images. Computers \& Geosciences, 22(5):525 - 534, June 1996.

[12] Matteo Frigo and Steven G. Johnson. The design and implementation of FFTW3. Proceedings of the IEEE, 93(2):216-231, 2005. Special issue on "Program Generation, Optimization, and Platform Adaptation".

[13] F. Vernier, R. Fallourd, J. M. Friedt, Y. Yan, E. Trouvé, J. M. Nicolas, and L. Moreau. Fast correlation technique for glacier flow monitoring by digital camera and space-borne sar images. EURASIP Journal on Image and Video Processing, 2011(11), 2011.

[14] Franklin C. Crow. Summed-area tables for texture mapping. In SIGGRAPH '84: Proceedings of the 11th annual conference on Computer graphics and interactive techniques, page 207212, New York, NY, USA, 1984. ACM.

[15] Paul Viola and Michael Jones. Robust real-time object detection. In International Journal of Computer Vision, 2001.

[16] H.-G. Maas, E. Schwalbe, R. Dietrich, M. Bässler, and H. Ewert. Determination of spatio-temporal velocity fields on glaciers in WestGreenland by terrestrial image sequence analysis. In IAPRS, Beijing, China, XXXVII, Part B8, pages 1419-1424, 2008.

[17] J.-M. Friedt, C. Ferrandez, G. Martin, L. Moreau, M. Griselin, E. Bernard, D. Laffly, and C. Marlin. Automated high resolution image acquisition in polar regions. In European Geosciences Union, Vienna, Austria, 2008.

[18] R. Fallourd, F. Vernier, J.-M. Friedt, G. Martin, E. Trouvé, L. Moreau, and J.-M. Nicolas. Monitoring temperate glacier with high resolution automated digital cameras - application to the Argentière glacier. In PCV 2010, ISPRS Commission III Symposium, Paris, France, 5 pages, Sept. 2010.
[19] William K. Pratt. Digital image processing. John Wiley \& Sons, Second edition, 1991

[20] W. D. Harrison, K. A. Echelmeyer, and D. M. Cosgrove. The determination of glacier speed by time-lapse photography under unfavorable conditions. Journal of Glaciology, 38(129):257-265, 1992. 